\title{
Neurocognitive and psychiatric markers for addiction: Common vs. specific (endo)phenotypes for opiate and stimulant dependence
}

\author{
Elizabeth C. Long ${ }^{1}$, Radka Kaneva ${ }^{2}$, Georgi Vasilev ${ }^{3}$, F. Gerard Moeller ${ }^{4,5}$, \\ Jasmin Vassileva ${ }^{4,5^{*}}$ \\ ${ }^{1}$ Edna Bennett Pierce Prevention Research Center, Pennsylvania State University, \\ University Park, PA \\ ${ }^{2}$ Department of Medical Chemistry and Biochemistry, Sofia Medical University, Sofia, \\ Bulgaria \\ ${ }^{3}$ Bulgarian Addictions Institute, Sofia, Bulgaria \\ ${ }^{4}$ Institute for Drug and Alcohol Studies, Virginia Commonwealth University, Richmond, \\ VA, USA \\ ${ }^{5}$ Department of Psychiatry, Virginia Commonwealth University, Richmond, VA, USA
}

*Corresponding author: Jasmin Vassileva, Virginia Commonwealth University, Institute for Drug and Alcohol Studies, 203 E. Cary St., P.O. Box 980059, Richmond, VA 232980059 (USA); E-mail: jasmin.vassileva@vcuhealth.org. 


\begin{abstract}
BACKGROUND. The differential utility of neurocognitive impulsivity and externalizing/internalizing traits as putative addiction endophenotypes among individuals dependent on opiates vs. stimulants is unclear. The present study aims to determine: (1) whether neurocognitive impulsivity dimensions and externalizing/internalizing traits are correlated between siblings discordant for opiate and stimulant dependence; and (2) which of these associations are common across substances and which are substancespecific. METHOD. Pearson correlations between individuals with 'pure' heroin and 'pure' amphetamine dependence and their unaffected biological siblings ( $n=37$ heroin sibling pairs; $n=30$ amphetamine sibling pairs) were run on 10 neurocognitive measures, 6 externalizing measures, and 5 internalizing measures. Sibling pair effects were further examined using regression. RESULTS. Siblings discordant for heroin dependence were significantly correlated on delay aversion on the Cambridge Gambling Task, risk-taking on the Balloon Analogue Risk Task, sensation seeking, and hopelessness. Siblings discordant for amphetamine dependence were significantly correlated on quality of decision-making on the Cambridge Gambling Task, discriminability on the Immediate Memory Task, commission errors on the Go/No-Go Task, trait impulsivity, ADHD, and anxiety sensitivity. CONCLUSIONS. Dimensions of impulsivity and externalizing/internalizing traits appear to aggregate among siblings discordant for substance dependence. Risk-taking propensity, sensation seeking, and hopelessness were specific for heroin sibling pairs. Motor/action impulsivity and trait impulsivity were specific to amphetamine sibling pairs. Decisional/choice impulsivity was common across both heroin and amphetamine sibling pairs. These findings provide preliminary evidence for the utility of neurocognitive impulsivity and externalizing/internalizing traits as candidate endophenotypes for substance dependence in general and for substancespecific dependencies.
\end{abstract}

Keywords: addiction; impulsivity; externalizing; internalizing; endophenotypes; discordant siblings 


\section{Introduction}

Twin and family studies have consistently shown that substance use disorders (SUDs) are influenced by genetic factors, with heritabilities on the order of $\sim 50 \%$ (Merikangas and McClair, 2012). However, heritability estimates can differ dramatically depending on specific drug classes, with heroin showing some of the highest unique heritability $(\sim 70 \%)$ relative to the much lower specific heritability of stimulants $(\sim 30 \%)$ (Goldman et al., 2005; Tsuang et al., 1998). Further, the high prevalence of polysubstance dependence in studies conducted in North America is recognized as a key source of sample heterogeneity in SUDs (Agrawal et al., 2007), leading to conflicting findings in the literature reporting SUD heritabilities. This heterogeneity and the complexity of SUDs explains in part why molecular genetic efforts, such as genome-wide association studies (GWAS), have failed to locate specific genes and to account for the same amount of genetic variance as twin studies.

A recent conceptual approach that can help reduce the heterogeneity of SUD phenotypes and provide a framework for identifying general and specific influences on SUDs is the "endophenotype" approach (Fineberg et al., 2010; Frederick and Iacono, 2006; Gilmore et al., 2010; Gottesman and Gould, 2003). Endophenotypes are measurable traits, intermediate between the clinical phenotype and the diseasesusceptibility genotype (Fineberg et al., 2010; Gottesman and Gould, 2003), thought to be genetically "simpler" than SUDs themselves. Neurocognitive functions are particularly suitable as endophenotypes and are more objective than self-report measures. As examples, there is evidence for executive function deficits as endophenotypes for ADHD (Gau and Shang, 2010; Rommelse et al., 2008); for processing speed, working memory, 
and facial memory as endophenotypes for bipolar disorder (Glahn et al., 2010); and for memory and emotion processing accuracy and speed of attention as endophenotypes for schizophrenia (Savitz et al., 2005).

Of the various neurocognitive functions implicated in SUDs, neurocognitive dimensions of impulsivity have received some of the strongest support as a candidate endophenotype for SUDs (Bickel, 2015; Frederick and Iacono, 2006; Kreek et al., 2005; MacKillop, 2013). Neurocognitive impulsivity is characterized by multiple dimensions that are typically measured with tasks falling into one of two categories (Winstanley et al., 2010): (1) Decisional/Choice impulsivity, which refers to the tendency to choose immediate but smaller rewards over delayed but larger rewards and may involve deficits in delaying gratification and exerting self-control (Fineberg et al., 2010), assessed with decision-making tasks involving various risk, reward, and delay contingencies (Fineberg et al., 2010; Hamilton et al., 2015b); and (2) Motor/Action impulsivity, which refers to the ability to refrain from inhibiting inappropriate behaviors, assessed with response inhibition tasks (Fineberg et al., 2014; Hamilton et al., 2015a). These impulsivity dimensions may differ in important ways between individuals who are dependent on different classes of drugs such as opiates and stimulants (Badiani et al., 2011; Ersche and Sahakian, 2007; Fernández-Serrano et al., 2011; George and Koob, 2010; Rogers et al., 1999; Verdejo-Garcia et al., 2007).

Of potential endophenotypic significance for SUDs are also traits and disorders within the externalizing and internalizing spectra, shown to be some of the most reliable risk factors for SUDs (Hussong et al., 2011; King et al., 2004; Krueger et al., 2002; Krueger et al., 2007). These traits are characterized by distinct neurocognitive profiles 
that most generally fall on a continuum between impulsivity and cognitive (over)control.

Externalizing traits are characterized by neurocognitive deficits in impulse control, including: (1) increased reward sensitivity (Bava and Tapert, 2010; Huijbregts et al., 2008; Stout et al., 2004; Stout et al., 2005); (2) decreased loss aversion (Ahn et al., 2014; Passarotti et al., 2010; Stout et al., 2004; Stout et al., 2005); (3) increased delay discounting (Kirby, K. N. et al., 1999; Reynolds, 2006; Reynolds and Fields, 2012); and (4) decreased response inhibition (Castellanos-Ryan et al., 2016; Castellanos-Ryan et al., 2011; Castellanos-Ryan et al., 2014; Nigg, 2000). In contrast, internalizing traits have been associated with a neurocognitive profile characterized by: (1) reward \& punishment processing abnormalities (Roiser and Sahakian, 2013; Smoski et al., 2008); (2) increased loss and risk aversion (Smoski et al., 2008); (3) decreased delay discounting (Lempert and Pizzagalli, 2010; Liu et al., 2012); (4) increased attentional lapses (Erickson et al., 2005); and (5) increased negative affect (Etkin et al., 2011; Mitterschiffthaler et al., 2008; Song et al., 2017; Surguladze et al., 2005; Williams et al., 1996).

Currently, it is unclear whether different dimensions of impulsivity and externalizing and internalizing traits/disorders have differential utility as putative endophenotypes of dependence among individuals dependent on opiates vs. those who are dependent on stimulants. We have the unique opportunity to examine this question and investigate the relationships between a large number of neurocognitive, externalizing, and internalizing phenotypes in a sibling-pair design via a research program we have developed in Bulgaria, where we have access to rare populations of 'pure' (i.e., monosubstance dependent) heroin and amphetamine users (Ahn et al., 2014; Ahn and 
Vassileva, 2016; Segalà et al., 2015; Vassileva et al., 2011; Vassileva et al., 2014;

Vassileva et al., 2007; Wilson and Vassileva, 2018; Wilson and Vassileva, 2016).

We specifically aim to (1) Investigate whether discrete neurocognitive dimensions of impulsivity as well as symptoms of externalizing and internalizing traits/disorders are correlated between siblings discordant for opiate and stimulant dependence, thereby providing preliminary evidence for their utility as candidate endophenotypes for SUDs; and (2) Determine which of these putative endophenotypes are common and which are substance-specific. We expect neurocognitive dimensions of impulsivity, externalizing traits/disorders, and internalizing traits/disorders to be correlated among individuals with SUDs and their unaffected siblings, which can provide evidence for their utility as endophenotypes. Further, based on previous findings (Ahn and Vassileva, 2016), we expect some to be common across substances and others to be substance-specific.

\section{Methods}

\subsection{Participants}

Participants were selected from a larger study of impulsivity among individuals with heroin and amphetamine dependence in Sofia, Bulgaria. Participants were recruited via flyers placed in substance abuse clinics, nightclubs, bars, and cafes in Sofia, as well as by word of mouth. Initial screening for medical and substance use histories was done by telephone and on-site. Inclusion criteria were as follows: (1) age between 18 and 50 years; (2) estimated IQ > 75; (3) minimum of 8th grade education; (4) no history of neurological illness; (5) HIV seronegative status; and (6) negative breathalyzer test for alcohol and negative urine toxicology screen for amphetamines, methamphetamines, cocaine, opiates, methadone, cannabis, benzodiazepines, barbiturates, and MDMA. 
In order to assess the utility of various personality, psychiatric, and neurocognitive measures as candidate endophenotypes for opiate and stimulant dependence, non-affected siblings of the participants with substance dependence were also recruited. Participants in the current study included 37 individuals with heroin dependence and 37 of their biological siblings with no history of substance dependence, as well as 30 individuals with amphetamine dependence and 30 of their non-dependent biological siblings. The majority of substance dependent individuals were in protracted abstinence (i.e. $>1$ year) at the time of testing. Critically, the majority of substance dependent individuals were mono-dependent on either heroin or amphetamines. There were a few participants with polysubstance dependence (9 in the heroin group and 7 in the amphetamine group), but these individuals were primarily dependent on the respective substance. The affected sibling with substance dependence was coded as 'Sibling 1', while the unaffected sibling was coded as 'Sibling 2'.

\subsection{Measures}

Participants were administered 7 commonly used neurocognitive tasks measuring different dimensions of impulsivity from which 10 performance indices were selected, 6 measures of externalizing traits and disorders, and 5 measures of internalizing traits and disorders. Substance dependence was measured with the Substance Abuse module of the Structured Clinical Interview for DSM-IV (SCID-I; (First and Gibbon, 2004)).

2.2.1 Neurocognitive tasks. While each of the 7 neurocognitive tasks generated several performance indices, we typically chose the most commonly used ones, as described below. For all measures except the Iowa Gambling Task and the Go/Stop Task, higher scores indicate higher levels of impulsivity. 


\subsubsection{Decisional/Choice Impulsivity:}

Iowa Gambling Task (IGT; (Bechara et al., 2000)). The IGT measures affective decision-making under conditions of ambiguity and uncertainty, which involves learning of rewards and punishment to guide decision-making. The total net score was used as the performance measure.

Cambridge Gambling Task (CGT; (Rogers et al., 1999)). The CGT, part of the Cambridge Neuropsychological Test Automated Battery (CANTAB; (Robbins et al., 1994)), is a probabilistic task indexing decision-making and risk-taking outside of a learning context, where no uncertainty is involved. We used delay aversion (DA) and the quality of decision-making (QDM) as the performance measures.

Monetary Choice Questionnaire (MCQ; (Kirby, Kris N et al., 1999)). The MCQ indexes delayed reward discounting (i.e., preference for smaller immediate rewards than larger delayed rewards). The $k$ discounting rate parameter (log-transformed) and the mean number of inconsistent responses (INC) were used as indices of performance. Unlike most other studies, we included INC because it provides additional information about choice consistency, which may be important to examine. Our group is currently testing novel computational models of delay discounting such as random utility models (Dai et al., 2016) that include choice consistency as a key parameter.

Balloon Analogue Risk Task (BART; (Lejuez et al., 2002)). The BART measures risk preferences and tolerance for exposure to risk in pursuit to a reward. We used the pumps adjusted average as a performance measure.

\subsubsection{Motor/Action Impulsivity:}


Immediate Memory Task (IMT; (Dougherty et al., 2003)). The IMT is a modified continuous performance task with complex demands on inhibitory control, working memory, and sustained attention. We selected two commonly used parameteric performance measures on the IMT: discriminability $\left(d^{\prime}\right)$ and response bias $(\beta)$.

Stop Signal Task (STOP; (Dougherty et al., 2003)). The task assesses the ability to withhold a prepotent response that has already been initiated. The performance measure used was the $150 \mathrm{msec}$ inhibition, calculated by dividing the failures to inhibit a response by the correct detections after a stop signal appearing $150 \mathrm{~ms}$ after the appearance of the target.

Go/No-Go Task (GNG; (Lane et al., 2007)). The GNG assesses the ability to inhibit prepotent responding. We used the number of commission errors as the performance measure.

2.2.2 Externalizing traits/disorders. Unless otherwise noted, the total scores on each of the 6 measures were used for the analyses.

Barratt Impulsiveness Scale $-11^{\text {th }}$ revision (BIS-11; (Patton et al., 1995)). The BIS is a 30 -item self-report scale assessing common impulsive behaviors. Participants were instructed to indicate the extent to which they agree with each item, ranging from 1 (rarely/never) to 4 (almost always/always).

Sensation Seeking Scale - Version V (SSS-V; (Zuckerman, 1996)). The SSS is a 40-item self-report scale reflecting a propensity to engage in novel, risky, or arousing types of behaviors. We used the existing (unpublished) Bulgarian version of the scale.

Buss-Warren Aggression Questionnaire (BUSS; (Buss and Warren, 2000)). The BUSS is a 34-item self-report screening for aggression, a prominent behavioral 
manifestation of impulsivity. We used the Bulgarian version of the scale (Popov et al., 2016a).

Wender Utah Rating Scale (WURS; (Ward et al., 1993)). The WURS is a selfreport scale used to evaluate adults for childhood symptoms of ADHD. We used the recently validated 25-item Bulgarian version of the scale (Nedelchev et al., 2016).

Antisocial Personality Disorder (ASPD). Symptom counts of antisocial personality disorder were obtained via the Antisocial Personality Module of the Structured Clinical Interview for DSM-IV (SCID-I; (First and Gibbon, 2004)).

Psychopathy Checklist, Screening Version (PCL:SV; (Hart et al., 1995)). The PCL:SV is a 12-item, interviewer-completed scale based on a semi-structured interview that assesses interpersonal/affective and antisocial psychopathy (Hare, 1991). The Bulgarian adaptation of the instrument (Wilson et al., 2014) was used.

2.2.3. Internalizing traits/disorders. Unless otherwise noted, the total scores on each of the 6 measures were used for the analyses.

Beck Depression Inventory - II (BDI-II; (Beck et al., 1996)). The BDI-II is a 21item scale that measures severity of depression symptoms during the last two weeks using a 4-point Likert Scale. We used the existing (unpublished) Bulgarian version of the scale.

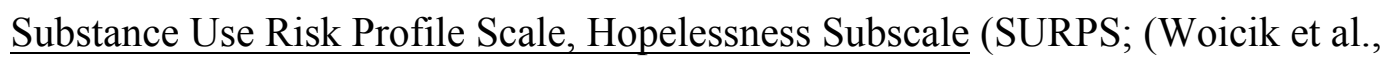
2009)). The SURPS is a 23 -item self-report scale assessing 4 personality traits associated with increased risk for substance misuse on a 4-point Likert Scale (impulsivity, sensation seeking, hopelessness, and anxiety sensitivity). We only used the hopelessness subscale 
because the other subscales overlap with other measures already included. We used the recently validated Bulgarian version of the SURPS (Long et al., 2018).

Anxiety Sensitivity Index (ANXSI; (Reiss et al., 1986)). The ANXSI is a 16-item, 5-point Likert scale that measures anxiety sensitivity as a global construct composed of several factors differentiating fear of specific anxiety symptoms and associated catastrophic consequences (Olthuis et al., 2014).

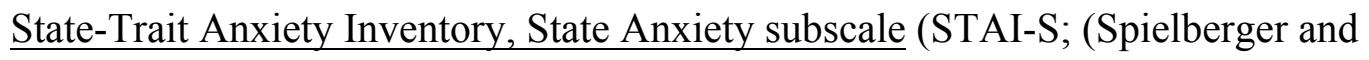
Jacobs, 1983)). The STAI is a 20 item, 4-point Likert scale that consists of Trait and State subscales. Only the State subscale was used. We used the existing Bulgarian adaptation (Shtetinski and Paspalanov, 2008).

Toronto Alexithymia Scale - 20 (TAS-20; (Bagby et al., 1994)). The TAS is a 20item scale designed to measure alexithymia associated with difficulties identifying and describing one's own feelings (Leising et al., 2009). We used the recently translated and validated Bulgarian version (Popov et al., 2016b).

\subsection{Analyses}

All analyses were conducted in R (R Development Core Team, 2013). Pearson correlations were run between individuals with heroin dependence and their nondependent biological siblings, and between individuals with amphetamine dependence and their non-dependent biological siblings, on the 10 neurocognitive measures, 6 externalizing measures, and 5 internalizing measures, using the corr.test function.

To further examine the extent to which neurocognitive, externalizing, and internalizing dimensions in the affected sibling predict these traits in the unaffected sibling, we ran linear regressions using the $l m$ function, with the independent variable 
being the dimensions for the affected sibling (sibling 1) and the dependent variable being the dimensions for the unaffected sibling (sibling 2). Separate models were run for each variable. Due to zero-inflation for ASPD, PCL:SV, and BDI-II, negative binomial regressions were run for these variables using the glm.nb function. Age and sex were included as covariates in all regression models. Directionality of the IGT and STOP was reversed for the correlations and regressions to maintain consistency across measures, such that high scores reflect high impulsivity on all measures.

\section{Results}

\subsection{Descriptive statistics}

The means and standard deviations (SDs) for the neurocognitive, externalizing, and internalizing measures are shown in Table 1, stratified by affected and unaffected siblings. For the neurocognitive measures, the means were fairly similar between the affected vs. unaffected siblings for both the discordant heroin and amphetamine pairs, with the exception of the BART, where the affected sibling demonstrated higher impulsivity. Opposite patterns of performance were observed between the discordant heroin pairs and discordant amphetamine pairs on the STOP Task and the GNG Task. For the discordant heroin pairs, the affected siblings scored higher on the STOP Task and the unaffected siblings scored higher on the GNG Task, whereas for the discordant amphetamine pairs the unaffected siblings scored higher on STOP Task and the affected siblings scored higher on the GNG Task. The unaffected siblings among the discordant amphetamine pairs also had a higher mean score on the IGT. Note that higher scores on the STOP Task and IGT indicate lower levels of impulsivity, whereas higher scores on all other measures indicate higher levels of impulsivity. For most of the externalizing and 
internalizing traits/disorders, the affected siblings had higher scores than the unaffected siblings, except for hopelessness among the discordant amphetamine pairs, where the siblings' scores were similar.

\subsection{Correlations between siblings discordant for SUDs}

The significant correlations between siblings discordant for SUDs on neurocognitive, externalizing, and internalizing measures are listed in Table 2 (please see Supplemental Tables 1, 2, and 3 for the full correlation matrices). The within-pair, within-trait (i.e., the correlations between sibling pairs on the same trait) correlations are shown in the top of the table, whereas the within-pair, cross-trait correlations (i.e., the correlations between sibling pairs on different traits) are shown in the bottom of the table.)

3.2.1 Neurocognitive measures. Among sibling pairs discordant for heroin dependence, there were significant positive within-trait sibling pair correlations on two measures of decisional/choice impulsivity: delay aversion on the CGT and pumps adjusted average on the BART. There were significant cross-trait positive correlations between discriminability on the IMT and inhibition on the STOP Task and between response bias on the IMT and inhibition on the STOP Task. There were significant crosstrait negative correlations between the discounting rate parameter $(k)$ on the MCQ and number of inconsistencies on the MCQ, and between commission errors on the GNG Task and discriminability on the IMT.

Among sibling pairs discordant for amphetamine dependence, there were significant within-trait positive correlations on two measures of motor/action impulsivity: discriminability on the IMT and commission errors on the GNG Task. There was also a 
significant within-trait positive correlation on a measure of decisional/choice impulsivity, quality of decision-making on the CGT. There were a number of significant cross-trait positive correlations: delay aversion on the CGT and inhibition on the STOP Task; discounting rate parameter $(k)$ on the MCQ and number of inconsistencies on the MCQ; response bias on the IMT and delay aversion on the CGT; inhibition on the STOP Task and commission errors on the GNG Task; and commission errors on the GNG Task and response bias on the IMT. There were also a number of significant cross-trait negative correlations: overall net score on the IGT and quality of decision making on the CGT; pumps adjusted average on the BART and overall net score on the IGT; discriminability on the IMT and response bias on the IMT; inhibition on the STOP Task and discriminability on the IMT; and commission errors on the GNG Task and discriminability on the IMT.

3.2.2 Externalizing traits/disorders. The sibling pairs discordant for heroin dependence were significantly and positively correlated on sensation seeking (SSS-V). There were no significant cross-trait positive correlations, but there were a number of significant cross-trait negative correlations between trait impulsivity (BIS-11) and psychopathy (PCL:SV); ADHD (WURS) and trait impulsivity (BIS-11); ADHD (WURS) and psychopathy (PCL:SV); and ASPD and trait impulsivity (BIS-11).

Among the sibling pairs discordant for amphetamine dependence there were significant within-trait positive correlations on trait impulsivity (BIS-11) and ADHD (WURS). There were a number of significant cross-trait positive correlations between sensation seeking (SSS-V) and trait impulsivity (BIS-11); ADHD (WURS) and trait impulsivity (BIS-11); ADHD (WURS) and aggression (BUSS); psychopathy (PCL:SV) 
and aggression (BUSS); and psychopathy (PCL:SV) and ADHD (WURS). There were no significant cross-trait negative correlations, which is the exact opposite pattern to the one we found with the siblings discordant for heroin dependence.

3.2.3 Internalizing Traits/Disorders. The sibling pairs discordant for heroin dependence were significantly and positively correlated on the Hopelessness subscale of the SURPS. There were a number of significant and positive cross-trait correlations: depression (BDI-II) and hopelessness (SURPS); depression (BDI-II) and alexithymia (TAS-20); hopelessness (SURPS) and alexithymia (TAS-20); state anxiety (STAI-S) and hopelessness (SURPS); and state anxiety (STAI-S) and alexithymia (TAS-20). There were no significant cross-trait negative correlations.

The sibling pairs discordant for amphetamine dependence were significantly and positively correlated on the Anxiety Sensitivity Index (ANXSI). There was only one significant cross-trait positive correlation between depression (BDI-II) and anxiety sensitivity (ANXSI). There were no significant cross-trait negative correlations.

\subsection{Regressions}

Finally, we examined the extent to which neurocognitive, externalizing, and internalizing dimensions in the affected sibling predict these dimensions in the unaffected sibling with linear and negative binomial regressions. These results are presented in Table 3. The patterns that were observed for the within-trait correlations were generally reflected in the regression results. For example, risk-taking (indexed by the BART), sensation seeking, and hopelessness in the siblings with heroin dependence significantly predicted these traits in the unaffected siblings. Although significantly correlated, delay 
aversion on the CGT did not reach statistical significance in the regression, though it was trending $(p=0.059)$.

Likewise, trait impulsivity (BIS-11), ADHD (WURS), and anxiety sensitivity (ANXSI) in the siblings with amphetamine dependence significantly predicted these traits in the unaffected siblings. However, the neurocognitive measures that were significantly correlated did not reach statistical significance (quality of decision making on the CGT, discriminability on the IMT, and commission errors on the GNG Task), but were similarly trending $(p=0.074, p=0.073$, and $p=0.059$, respectively).

\section{Discussion}

Using a sample of Bulgarian individuals with 'pure' heroin and amphetamine dependence and their unaffected siblings, we investigated sibling pair correlations on neurocognitive dimensions of impulsivity, externalizing traits/disorders, and internalizing traits/disorders in order to explore their potential utility as common vs. specific endophenotypes for opiate and stimulant dependence. Results revealed both common and substance-specific associations. Decisional/choice impulsivity was common across both heroin and amphetamine sibling pairs (delay aversion on the CGT and BART for discordant heroin pairs; quality of decision making on the CGT for discordant amphetamine pairs), whereas motor/action impulsivity (discriminability on the IMT and commission errors on the GNG) was specific to amphetamine sibling pairs. Sensation seeking (SSS-V) and hopelessness (SURPS-H) were specific to discordant heroin sibling pairs, whereas trait impulsivity (BIS-11), ADHD (WURS), and anxiety sensitivity (ANXSI) were specific to discordant amphetamine sibling pairs. These results are consistent with previous literature showing that impulsivity and anxious-impulsive 
personality traits, but not sensation seeking, are candidate endophenotypes for stimulant dependence (Ersche et al., 2012; Ersche et al., 2010).

Of interest is the opposite direction of effects for some of the cross-trait correlations among the discordant heroin sibling pairs compared to the discordant amphetamine sibling pairs. The correlation between the delay discounting parameter $k$ and the number of inconsistencies on the MCQ was positive for the discordant heroin pairs, but negative for the discordant amphetamine pairs. This pattern of results suggests that the discordant heroin pairs performed similarly on these measures, whereas the discordant amphetamine pairs differed in their performance, highlighting the value of adding the inconsistency measure. We believe this measure may offer useful information, as evidenced by the current results, and are currently testing novel computational models of delay discounting which include choice variability as a key parameter (Kvam et al., 2018).

Additionally, all the significant cross-trait correlations for the externalizing traits were negative for the discordant heroin pairs, but positive for the discordant amphetamine pairs. There were also many more significant cross-trait correlations for the internalizing traits among the discordant heroin pairs relative to the discordant amphetamine pairs. Together, these results suggest that the externalizing spectrum aggregates in siblings discordant for amphetamine dependence, whereas the internalizing spectrum aggregates in siblings discordant for heroin dependence. This is in line with previous work from our group, which similarly shows that internalizing traits such as depression and anxiety are significant predictors of heroin but not amphetamine 
dependence, whereas externalizing traits such as disinhibited sensation seeking and hostility predict amphetamine but not heroin dependence (Ahn and Vassileva, 2016).

One potential explanation for why internalizing traits may be endophenotypes specific to heroin dependence may be related to the notion of "hyperkatifeia," which refers to increases in emotional distress and emotional pain experienced during withdrawal and abstinence from chronic drug use (Shurman et al., 2010). It is possible that individuals who are genetically predisposed to internalizing disorders are more likely to find the analgesic effects of opiates more reinforcing than individuals who are genetically predisposed to externalizing disorders.

Finally, our findings highlight the utility of simultaneously examining multiple neurocognitive, externalizing, and internalizing dimensions. Research indicates that the most powerful genetic approaches often involve multivariate, rather than univariate analyses of individual characteristics and traits (Iacono et al., 2018). Similarly, it has been noted that examination of multivariate candidate (endo)phenotypes may increase the power to detect genetic effects (Van Der Sluis et al., 2010). One pervasive problem in genetic association studies is the "missing heritability" problem, namely that the variance explained by genetic variants from GWAS studies is very small compared to the heritability estimates obtained from family studies (Van Der Sluis et al., 2010). While genetic heterogeneity is often invoked as an explanation, the manner in which complex phenotypic traits are measured and modeled are equally important contributors to the "missing heritability" problem but have received much less attention in the literature. Despite the multidimensionality of traits measured by psychometric, diagnostic, and neurocognitive instruments, most GWAS studies typically use total sum scores that do 
not reflect the underlying phenotypic multidimensionality. The current findings may inform future multivariate multilevel models of complex phenotypes and increase understanding of the complex relationship between multiple neurocognitive and personality phenotypes that may help redefine putative endophenotypes as multi-level combination of measures (Bilder et al., 2009), the next critical step in the endophenotype approach (Sabb et al., 2009).

\section{Limitations}

Despite clear strengths of the present study (e.g., use of rare individuals with "pure" dependencies; comprehensive assessment of impulsivity, externalizing and internalizing dimensions, inclusion of non-affected biological siblings), our findings should be considered within the context of two limitations. First, our sample size was small. Second, our sample consisted entirely of individuals from Bulgaria. Although this limitation was necessary to permit use of individuals with pure dependencies, it is unclear if our findings will generalize to other populations.

\section{Conclusion}

Neurocognitive dimensions of impulsivity, externalizing, and internalizing traits appear to aggregate differentially among siblings discordant for heroin and amphetamine dependence. These findings provide preliminary evidence for the utility of these traits as common and specific candidate endophenotypes for opiate and stimulant dependence. 
Funding: This work was supported by the National Institute on Drug Abuse and the Fogarty International Center at NIH under award number R01DA021421 (JV).

Conflicts of Interest: GV discloses that he has ownership interests in the Bulgarian Addictions Institute, where data collection took place. 


\section{References}

Agrawal, A., Lynskey, M.T., Madden, P.A., Bucholz, K.K., Heath, A.C., 2007. A latent class analysis of illicit drug abuse/dependence: results from the National Epidemiological Survey on Alcohol and Related Conditions. Addiction 102(1), 94-104.

Ahn, W.Y., Vasilev, G., Lee, S.H., Busemeyer, J.R., Kruschke, J.K., Bechara, A., Vassileva, J., 2014. Decision-making in stimulant and opiate addicts in protracted abstinence: evidence from computational modeling with pure users. Front Psychol 5, 849.

Ahn, W.Y., Vassileva, J., 2016. Machine-learning identifies substance-specific behavioral markers for opiate and stimulant dependence. Drug Alcohol Depend 161, 247257.

Badiani, A., Belin, D., Epstein, D., Calu, D., Shaham, Y., 2011. Opiate versus psychostimulant addiction: the differences do matter. Nature Reviews Neuroscience 12(11), 685-700.

Bagby, R.M., Parker, J.D., Taylor, G.J., 1994. The twenty-item Toronto Alexithymia Scale--I. Item selection and cross-validation of the factor structure. J Psychosom Res $38(1), 23-32$.

Bava, S., Tapert, S.F., 2010. Adolescent brain development and the risk for alcohol and other drug problems. Neuropsychol Rev 20(4), 398-413.

Bechara, A., Tranel, D., Damasio, H., 2000. Characterization of the decision-making deficit of patients with ventromedial prefrontal cortex lesions. Brain 123(11), 2189-2202.

Beck, A.T., Steer, R.A., Brown, G.K., 1996. Beck depression inventory-II. San Antonio 78(2), 490-498.

Bickel, W.K., 2015. Discounting of Delayed Rewards as an Endophenotype. Biological Psychiatry 77(10), 846-847.

Bilder, R.M., Sabb, F., Cannon, T., London, E., Jentsch, J., Parker, D.S., Poldrack, R., Evans, C., Freimer, N., 2009. Phenomics: the systematic study of phenotypes on a genome-wide scale. Neuroscience 164(1), 30-42.

Buss, A.H., Warren, W.L., 2000. Aggression questionnaire (AQ). Manual. Western Psychological Services.

Castellanos-Ryan, N., Briere, F.N., O'Leary-Barrett, M., Banaschewski, T., Bokde, A., Bromberg, U., Buchel, C., Flor, H., Frouin, V., Gallinat, J., Garavan, H., Martinot, J.L., Nees, F., Paus, T., Pausova, Z., Rietschel, M., Smolka, M.N., Robbins, T.W., Whelan, R., Schumann, G., Conrod, P., Consortium, I., 2016. The structure of psychopathology in 
adolescence and its common personality and cognitive correlates. J Abnorm Psychol 125(8), 1039-1052.

Castellanos-Ryan, N., Rubia, K., Conrod, P.J., 2011. Response inhibition and reward response bias mediate the predictive relationships between impulsivity and sensation seeking and common and unique variance in conduct disorder and substance misuse. Alcohol Clin Exp Res 35(1), 140-155.

Castellanos-Ryan, N., Struve, M., Whelan, R., Banaschewski, T., Barker, G.J., Bokde, A.L., Bromberg, U., Buchel, C., Flor, H., Fauth-Buhler, M., Frouin, V., Gallinat, J., Gowland, P., Heinz, A., Lawrence, C., Martinot, J.L., Nees, F., Paus, T., Pausova, Z., Rietschel, M., Robbins, T.W., Smolka, M.N., Schumann, G., Garavan, H., Conrod, P.J., Consortium, I., 2014. Neural and cognitive correlates of the common and specific variance across externalizing problems in young adolescence. Am J Psychiatry 171(12), 1310-1319.

Dai, J., Gunn, R.L., Gerst, K.R., Busemeyer, J.R., Finn, P.R., 2016. A random utility model of delay discounting and its application to people with externalizing psychopathology. Psychol Assess 28(10), 1198-1206.

Dougherty, D.M., Bjork, J.M., Andrew Harper, R., Marsh, D.M., Gerard Moeller, F., Mathias, C.W., Swann, A.C., 2003. Behavioral impulsivity paradigms: a comparison in hospitalized adolescents with disruptive behavior disorders. Journal of Child Psychology and Psychiatry 44(8), 1145-1157.

Erickson, K., Drevets, W.C., Clark, L., Cannon, D.M., Bain, E.E., Zarate, C.A., Jr., Charney, D.S., Sahakian, B.J., 2005. Mood-congruent bias in affective go/no-go performance of unmedicated patients with major depressive disorder. Am J Psychiatry 162(11), 2171-2173.

Ersche, K.D., Sahakian, B.J., 2007. The neuropsychology of amphetamine and opiate dependence: implications for treatment. Neuropsychology review 17(3), 317-336.

Ersche, K.D., Turton, A.J., Chamberlain, S.R., Müller, U., Bullmore, E.T., Robbins, T.W., 2012. Cognitive dysfunction and anxious-impulsive personality traits are endophenotypes for drug dependence. American Journal of Psychiatry 169(9), 926-936.

Ersche, K.D., Turton, A.J., Pradhan, S., Bullmore, E.T., Robbins, T.W., 2010. Drug addiction endophenotypes: impulsive versus sensation-seeking personality traits. Biological psychiatry 68(8), 770-773.

Etkin, A., Egner, T., Kalisch, R., 2011. Emotional processing in anterior cingulate and medial prefrontal cortex. Trends in cognitive sciences 15(2), 85-93. 
Fernández-Serrano, M.J., Pérez-García, M., Verdejo-García, A., 2011. What are the specific vs. generalized effects of drugs of abuse on neuropsychological performance? Neuroscience \& Biobehavioral Reviews 35(3), 377-406.

Fineberg, N.A., Chamberlain, S.R., Goudriaan, A.E., Stein, D.J., Vanderschuren, L.J., Gillan, C.M., Shekar, S., Gorwood, P.A., Voon, V., Morein-Zamir, S., 2014. New developments in human neurocognition: clinical, genetic, and brain imaging correlates of impulsivity and compulsivity. CNS spectrums 19(1), 69-89.

Fineberg, N.A., Potenza, M.N., Chamberlain, S.R., Berlin, H.A., Menzies, L., Bechara, A., Sahakian, B.J., Robbins, T.W., Bullmore, E.T., Hollander, E., 2010. Probing compulsive and impulsive behaviors, from animal models to endophenotypes: a narrative review. Neuropsychopharmacology 35(3), 591-604.

First, M.B., Gibbon, M., 2004. The Structured Clinical Interview for DSM-IV Axis I Disorders (SCID-I) and the Structured Clinical Interview for DSM-IV Axis II Disorders (SCID-II).

Frederick, J.A., Iacono, W.G., 2006. Beyond the DSM: defining endophenotypes for genetic studies of substance abuse. Current Psychiatry Reports 8(2), 144.

Gau, S.S.F., Shang, C.Y., 2010. Executive functions as endophenotypes in ADHD: evidence from the Cambridge Neuropsychological Test Battery (CANTAB). Journal of Child Psychology and Psychiatry 51(7), 838-849.

George, O., Koob, G.F., 2010. Individual differences in prefrontal cortex function and the transition from drug use to drug dependence. Neuroscience and Biobehavioral Reviews $35(2), 232-247$.

Gilmore, C.S., Malone, S.M., Iacono, W.G., 2010. Brain electrophysiological endophenotypes for externalizing psychopathology: a multivariate approach. Behav Genet 40(2), 186-200.

Glahn, D.C., Almasy, L., Barguil, M., Hare, E., Peralta, J.M., Kent, J.W., Dassori, A., Contreras, J., Pacheco, A., Lanzagorta, N., Nicolini, H., Raventos, H., Escamilla, M.A., 2010. Neurocognitive Endophenotypes for Bipolar Disorder Identified in Multiplex Multigenerational Families. Archives of General Psychiatry 67(2), 168-177.

Goldman, D., Oroszi, G., Ducci, F., 2005. The genetics of addictions: uncovering the genes. Nat Rev Genet 6(7), 521-532.

Gottesman, II, Gould, T.D., 2003. The endophenotype concept in psychiatry: etymology and strategic intentions. Am J Psychiatry 160(4), 636-645.

Hamilton, K.R., Littlefield, A.K., Anastasio, N.C., Cunningham, K.A., Fink, L.H.L., Wing, V.C., Mathias, C.W., Lane, S.D., Schütz, C.G., Swann, A.C., Lejuez, C.W., Clark, 
L., Moeller, F.G., Potenza, M.N., 2015a. Rapid-response impulsivity: definitions, measurement issues, and clinical implications. Personality Disorders 6(2), 168-181.

Hamilton, K.R., Mitchell, M.R., Wing, V.C., Balodis, I.M., Bickel, W.K., Fillmore, M., Lane, S.D., Lejuez, C., Littlefield, A.K., Luijten, M., 2015b. Choice impulsivity: Definitions, measurement issues, and clinical implications. Personality Disorders: Theory, Research, and Treatment 6(2), 182.

Hare, R.D., 1991. The Hare psychopathy checklist-revised: Manual. Multi-Health Systems, Incorporated.

Hart, S.D., Cox, D.N., Hare, R.D., 1995. Hare psychopathy checklist: Screening version (PCL: SV). Multi-Heath Systems.

Huijbregts, S.C., Warren, A.J., de Sonneville, L.M., Swaab-Barneveld, H., 2008. Hot and cool forms of inhibitory control and externalizing behavior in children of mothers who smoked during pregnancy: an exploratory study. J Abnorm Child Psychol 36(3), 323-333.

Hussong, A.M., Jones, D.J., Stein, G.L., Baucom, D.H., Boeding, S., 2011. An Internalizing Pathway to Alcohol Use and Disorder. Psychology of Addictive Behaviors 25(3), 390-404.

Iacono, W.G., Heath, A.C., Hewitt, J.K., Neale, M.C., Banich, M.T., Luciana, M.M., Madden, P.A., Barch, D.M., Bjork, J.M., 2018. The utility of twins in developmental cognitive neuroscience research: How twins strengthen the ABCD research design. Developmental cognitive neuroscience 32, 30-42.

King, S.M., Iacono, W.G., McGue, M., 2004. Childhood externalizing and internalizing psychopathology in the prediction of early substance use. Addiction 99(12), 1548-1559.

Kirby, K.N., Petry, N.M., Bickel, W.K., 1999. Heroin addicts have higher discount rates for delayed rewards than non-drug-using controls. Journal of Experimental psychology: general 128(1), 78 .

Kirby, K.N., Petry, N.M., Bickel, W.K., 1999. Heroin addicts have higher discount rates for delayed rewards than non-drug-using controls. J Exp Psychol Gen 128(1), 78-87.

Kreek, M.J., Nielsen, D.A., Butelman, E.R., LaForge, K.S., 2005. Genetic influences on impulsivity, risk taking, stress responsivity and vulnerability to drug abuse and addiction. Nat Neurosci 8(11), 1450-1457.

Krueger, R.F., Hicks, B.M., Patrick, C.J., Carlson, S.R., Iacono, W.G., McGue, M., 2002. Etiologic connections among substance dependence, antisocial behavior, and personality: Modeling the externalizing spectrum. Journal of Abnormal Psychology 111(3), 411-424. 
Krueger, R.F., Markon, K.E., Patrick, C.J., Benning, S.D., Kramer, M.D., 2007. Linking antisocial behavior, substance use, and personality: an integrative quantitative model of the adult externalizing spectrum. Journal of Abnormal Psychology 116(4), 645-666.

Kvam, P., Romeu, R., Turner, B. M., Vassileva, J., Busemeyer, J. R. (2018). Connecting behavior across tasks using joint cognitive models: Impulsivity in delay discounting and Cambridge gambling tasks. 59th Annual Meeting of the Psychonomic Society, New Orleans, LA.

Lane, S.D., Moeller, F.G., Steinberg, J.L., Buzby, M., Kosten, T.R., 2007. Performance of cocaine dependent individuals and controls on a response inhibition task with varying levels of difficulty. Am J Drug Alcohol Abuse 33(5), 717-726.

Leising, D., Grande, T., Faber, R., 2009. The Toronto Alexithymia Scale (TAS-20): A measure of general psychological distress. Journal of Research in Personality 43(4), 707710.

Lejuez, C.W., Read, J.P., Kahler, C.W., Richards, J.B., Ramsey, S.E., Stuart, G.L., Strong, D.R., Brown, R.A., 2002. Evaluation of a behavioral measure of risk taking: the Balloon Analogue Risk Task (BART). J Exp Psychol Appl 8(2), 75-84.

Lempert, K.M., Pizzagalli, D.A., 2010. Delay discounting and future-directed thinking in anhedonic individuals. J Behav Ther Exp Psychiatry 41(3), 258-264.

Liu, R.T., Vassileva, J., Gonzalez, R., Martin, E.M., 2012. A comparison of delay discounting among substance users with and without suicide attempt history. Psychol Addict Behav 26(4), 980-985.

Long, E.C., Milcheva, S., Psederska, E., Vasilev, G.N., Bozgunov, K., Nedelchev, D., Gillespie, N.A., Vassileva, J., 2018. Validation of the Substance Use Risk Profile Scale (SURPS) with Bulgarian Substance Dependent Individuals. Frontiers in Psychology 9.

MacKillop, J., 2013. Integrating behavioral economics and behavioral genetics: delayed reward discounting as an endophenotype for addictive disorders. Journal of the experimental analysis of behavior 99(1), 14-31.

Merikangas, K.R., McClair, V.L., 2012. Epidemiology of substance use disorders. Human Genetics 131(6), 779-789.

Mitterschiffthaler, M., Williams, S., Walsh, N., Cleare, A., Donaldson, C., Scott, J., Fu, C., 2008. Neural basis of the emotional Stroop interference effect in major depression. Psychological medicine 38(2), 247-256.

Nedelchev, D., Popov, V., Psederska, E., Bozgunov, K., Vasilev, G., Peneva, E., Vassileva, J., 2016. Psychometric Characteristics of the Bulgarian version of the Wender 
Utah Rating Scale (WURS-25) for ADHD (in Bulgarian). Clinical and Consulting Psychology 2(28), 3-17.

Nigg, J.T., 2000. On inhibition/disinhibition in developmental psychopathology: views from cognitive and personality psychology and a working inhibition taxonomy. Psychol Bull 126(2), 220-246.

Olthuis, J.V., Watt, M.C., Stewart, S.H., 2014. Anxiety Sensitivity Index (ASI-3) subscales predict unique variance in anxiety and depressive symptoms. Journal of Anxiety Disorders 28(2), 115-124.

Passarotti, A.M., Sweeney, J.A., Pavuluri, M.N., 2010. Neural correlates of response inhibition in pediatric bipolar disorder and attention deficit hyperactivity disorder. Psychiatry Res 181(1), 36-43.

Patton, J.H., Stanford, M.S., Barratt, E.S., 1995. Factor structure of the Barratt impulsiveness scale. Journal of clinical psychology 51(6), 768-774.

Popov, V., Nedelchev, D., Psederska, E., Georgieva, V., Bozgunov, K., Vasilev, G., Vassileva, J., 2016a. Psychometric characterstics of the Bulgarian version of the BussWarren Aggression Questionnaire (BWAQ). (in Bulgarian). Clinical and Consulting Psychology 4(30), 37-53.

Popov, V., Psederska, E., Peneva, E., Bozgunov, K., Vasilev, G., Nedelchev, D., Vassileva, J., 2016b. Psychometric characteristics of the Bulgarian version of the Toronto Alexithymia Scale (TAS-20) (in Bulgarian). Psychological Research 19(2), 25-42.

R Development Core Team, 2013. R: A language and environment for statistical computing. R Foundation for Statistical Computing, Vienna, Austria.

Reiss, S., Peterson, R.A., Gursky, D.M., McNally, R.J., 1986. Anxiety sensitivity, anxiety frequency and the prediction of fearfulness. Behav Res Ther 24(1), 1-8.

Reynolds, B., 2006. A review of delay-discounting research with humans: relations to drug use and gambling. Behav Pharmacol 17(8), 651-667.

Reynolds, B., Fields, S., 2012. Delay discounting by adolescents experimenting with cigarette smoking. Addiction 107(2), 417-424.

Robbins, T.W., James, M., Owen, A.M., Sahakian, B.J., McInnes, L., Rabbitt, P., 1994. Cambridge Neuropsychological Test Automated Battery (CANTAB): a factor analytic study of a large sample of normal elderly volunteers. Dementia and Geriatric Cognitive Disorders 5(5), 266-281.

Rogers, R.D., Everitt, B.J., Baldacchino, A., Blackshaw, A.J., Swainson, R., Wynne, K., Baker, N.B., Hunter, J., Carthy, T., Booker, E., London, M., Deakin, J.F., Sahakian, B.J., 
Robbins, T.W., 1999. Dissociable deficits in the decision-making cognition of chronic amphetamine abusers, opiate abusers, patients with focal damage to prefrontal cortex, and tryptophan-depleted normal volunteers: evidence for monoaminergic mechanisms. Neuropsychopharmacology 20(4), 322-339.

Roiser, J.P., Sahakian, B.J., 2013. Hot and cold cognition in depression. CNS Spectr 18(3), 139-149.

Rommelse, N., Altink, M., Oosterlaan, J., Buschgens, C., Buitelaar, J., Sergeant, J., 2008. Support for an independent familial segregation of executive and intelligence endophenotypes in ADHD families. Psychological medicine 38(11), 1595-1606.

Sabb, F., Burggren, A., Higier, R., Fox, J., He, J., Parker, D., Poldrack, R., Chu, W., Cannon, T., Freimer, N., 2009. Challenges in phenotype definition in the whole-genome era: multivariate models of memory and intelligence. Neuroscience 164(1), 88-107.

Savitz, J.B., Solms, M., Ramesar, R.S., 2005. Neurocognitive function as an endophenotype for genetic studies of bipolar affective disorder. Neuromolecular Medicine 7(4), 275-286.

Segalà, L., Vasilev, G., Raynov, I., Gonzalez, R., Vassileva, J., 2015. Childhood Symptoms of ADHD and Impulsivity in Abstinent Heroin Users. J Dual Diagn 11(3-4), 174-178.

Shtetinski, D., Paspalanov, I., 2008. STAI-Y: A questionnaire for the assessment of state and trait anxiety. OS Bulgaria, Sofia, Bulgaria.

Shurman, J., Koob, G.F., Gutstein, H.B., 2010. Opioids, pain, the brain, and hyperkatifeia: a framework for the rational use of opioids for pain. Pain Medicine 11(7), 1092-1098.

Smoski, M.J., Lynch, T.R., Rosenthal, M.Z., Cheavens, J.S., Chapman, A.L., Krishnan, R.R., 2008. Decision-making and risk aversion among depressive adults. J Behav Ther Exp Psychiatry 39(4), 567-576.

Song, S., Zilverstand, A., Song, H., Uquillas, F.d.O., Wang, Y., Xie, C., Cheng, L., Zou, Z., 2017. The influence of emotional interference on cognitive control: A meta-analysis of neuroimaging studies using the emotional Stroop task. Scientific reports 7(1), 2088.

Spielberger, C.D., Gorsuch, R. L., Lushene, R., Vagg, P. R.,, Jacobs, G.A., 1983. Manual for the State-Trait Anxiety Inventory. Palo Alto, CA: Consulting Psychologists Press.

Stout, J.C., Busemeyer, J.R., Lin, A., Grant, S.J., Bonson, K.R., 2004. Cognitive modeling analysis of decision-making processes in cocaine abusers. Psychon Bull Rev 11(4), 742-747. 
Stout, J.C., Rock, S.L., Campbell, M.C., Busemeyer, J.R., Finn, P.R., 2005.

Psychological processes underlying risky decisions in drug abusers. Psychol Addict Behav 19(2), 148-157.

Surguladze, S., Brammer, M.J., Keedwell, P., Giampietro, V., Young, A.W., Travis, M.J., Williams, S.C., Phillips, M.L., 2005. A differential pattern of neural response toward sad versus happy facial expressions in major depressive disorder. Biological psychiatry 57(3), 201-209.

Tsuang, M.T., Lyons, M.J., Meyer, J.M., Doyle, T., Eisen, S.A., Goldberg, J., True, W., Lin, N., Toomey, R., Eaves, L., 1998. Co-occurrence of abuse of different drugs in men: the role of drug-specific and shared vulnerabilities. Arch Gen Psychiatry 55(11), 967972.

Van Der Sluis, S., Verhage, M., Posthuma, D., Dolan, C.V., 2010. Phenotypic complexity, measurement bias, and poor phenotypic resolution contribute to the missing heritability problem in genetic association studies. PloS one 5(11), e13929.

Vassileva, J., Georgiev, S., Martin, E., Gonzalez, R., Segalà, L., 2011. Psychopathic heroin addicts are not uniformly impaired across neurocognitive domains of impulsivity. Drug and alcohol dependence 114(2-3), 194-200.

Vassileva, J., Paxton, J., Moeller, F.G., Wilson, M.J., Bozgunov, K., Martin, E.M., Gonzalez, R., Vasilev, G., 2014. Heroin and amphetamine users display opposite relationships between trait and neurobehavioral dimensions of impulsivity. Addictive behaviors 39(3), 652-659.

Vassileva, J., Petkova, P., Georgiev, S., Martin, E.M., Tersiyski, R., Raycheva, M., Velinov, V., Marinov, P., 2007. Impaired decision-making in psychopathic heroin addicts. Drug Alcohol Depend 86(2-3), 287-289.

Verdejo-Garcia, A.J., Perales, J.C., Perez-Garcia, M., 2007. Cognitive impulsivity in cocaine and heroin polysubstance abusers. Addict Behav 32(5), 950-966.

Ward, M.F., Wender, P.H., Reimherr, F.W., 1993. The Wender Utah Rating Scale: an aid in the retrospective diagnosis of childhood attention deficit hyperactivity disorder. The American journal of psychiatry 150(6), 885-890.

Williams, J.M.G., Mathews, A., MacLeod, C., 1996. The emotional Stroop task and psychopathology. Psychological bulletin 120(1), 3.

Wilson, M.J., Abramowitz, C., Vasilev, G., Bozgunov, K., Vassileva, J., 2014. Psychopathy in Bulgaria: The cross-cultural generalizability of the Hare Psychopathy Checklist. J Psychopathol Behav Assess 36(3), 389-400. 
Wilson, M.J., Vassileva, J., 2016. Neurocognitive and psychiatric dimensions of hot, but not cool, impulsivity predict HIV sexual risk behaviors among drug users in protracted abstinence. The American journal of drug and alcohol abuse 42(2), 231-241.

Wilson, M., Vassileva, J., 2018. Decision-making under risk, but not under ambiguity, predicts pathological gambling in discrete types of abstinent substance users. Frontiers in Psychiatry 9.

Woicik, P.A., Stewart, S.H., Pihl, R.O., Conrod, P.J., 2009. The Substance Use Risk Profile Scale: a scale measuring traits linked to reinforcement-specific substance use profiles. Addictive behaviors 34(12), 1042-1055.

Zuckerman, M., 1996. The psychobiological model for impulsive unsocialized sensation seeking: a comparative approach. Neuropsychobiology 34(3), 125-129. 
bioRxiv preprint doi: https://doi.org/10.1101/480970; this version posted November 29, 2018. The copyright holder for this preprint (which was

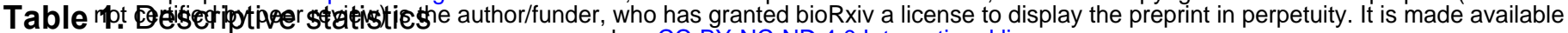

\begin{tabular}{|c|c|c|}
\hline \multirow{2}{*}{ Neurocognitive Measures, mean (SD) } & \multicolumn{2}{|c|}{$\begin{array}{l}\text { ficensibling Pairs Discordant for Heroin } \\
\text { Dependence, } N=37\end{array}$} \\
\hline & Affected Sibling & Unaffected Sibling \\
\hline lowa Gambling Task (IGT), Net Score & $-0.66(23.69)$ & $-0.81(29.78)$ \\
\hline Cambridge Gabling Task (CGT), Delay aversion & $0.29(0.21)$ & $0.37(0.24)$ \\
\hline Cambridge Gabling Task (CGT), Quality of decision making & $0.86(0.15)$ & $0.88(0.09)$ \\
\hline Monetary Choice Questionnaire (MCQ), Log overall $k$ & $-1.48(0.65)$ & $-1.55(0.68)$ \\
\hline Monetary Choice Questionnaire (MCQ), \# of inconsistencies & $0.21(0.42)$ & $0.62(1.09)$ \\
\hline Balloon Analogue Risk Task (BART), Pumps adjusted average & $42.20(12.48)$ & $37.52(14.76)$ \\
\hline Immediate Memory Task (IMT), Discriminability $\left(d^{\prime}\right)$ & $1.32(0.54)$ & $1.29(0.43)$ \\
\hline Immediate Memory Task (IMT), Response bias ( $\beta$ ) & $0.75(0.43)$ & $0.84(0.43)$ \\
\hline Go/Stop Task (STOP), 150 msec inhibition & $73.57(17.13)$ & $70.68(20.89)$ \\
\hline Go/No-Go Task (GNG), Commission errors & $13.44(8.45)$ & $16.59(11.94)$ \\
\hline \multicolumn{3}{|l|}{ Externalizing Traits/Disorders, mean (SD) } \\
\hline Barratt Impulsiveness Scale-11 (BIS-11) & $61.67(10.40)$ & $56.03(7.61)$ \\
\hline Sensation Seeking Scale (SSS-V) & $18.83(7.16)$ & $17.49(7.34)$ \\
\hline Buss Warren Aggression Questionnaire (BUSS) & $44.42(9.28)$ & $38.03(9.33)$ \\
\hline Wender Utah Rating Scale for ADHD (WURS) & $37.54(19.64)$ & $20.16(11.47)$ \\
\hline Antisocial Personality Disorder (ASPD), \# of symptoms & $3.78(1.89)$ & $0.19(0.57)$ \\
\hline Psychopathy Checklist (PCL:SV) & $12.56(4.99)$ & $2.54(2.57)$ \\
\hline \multicolumn{3}{|l|}{ Internalizing Traits/Disorders, mean (SD) } \\
\hline Beck Depression Inventory II (BDI-II) & $7.31(5.31)$ & $6.30(7.13)$ \\
\hline Hopelessness, Substance Use Risk Profile (SURPS) & $12.87(3.96)$ & $12.61(3.59)$ \\
\hline Anxiety Sensitivity Index (ANXSI) & $19.35(9.46)$ & $17.05(8.24)$ \\
\hline State Anxiety (STAI) & $33.78(7.23)$ & $32.35(10.15)$ \\
\hline \multirow[t]{3}{*}{ Toronto Alexithymia Scale (TAS) } & $47.07(10.72)$ & $44.32(9.66)$ \\
\hline & \multicolumn{2}{|c|}{$\begin{array}{c}\text { Sibling Pairs Discordant for } \\
\text { Amphetamine Dependence, } N=30\end{array}$} \\
\hline & Affected Sibling & Unaffected Sibling \\
\hline \multicolumn{3}{|l|}{ Neurocognitive Measures, mean (SD) } \\
\hline lowa Gambling Task (IGT), Total Net Score & $0.72(26.53)$ & $5.66(27.59)$ \\
\hline Cambridge Gabling Task (CGT), Delay aversion & $0.31(0.18)$ & $0.25(0.19)$ \\
\hline Cambridge Gabling Task (CGT), Quality of decision making & $0.89(0.08)$ & $0.88(0.19)$ \\
\hline Monetary Choice Questionnaire (MCQ), Log overall $k$ & $-1.49(0.53)$ & $-1.68(0.61)$ \\
\hline Monetary Choice Questionnaire (MCQ), \# of inconsistencies & $0.33(0.61)$ & $0.63(1.19)$ \\
\hline Balloon Analogue Risk Task (BART), Pumps adjusted average & $45.49(13.12)$ & $42.50(12.94)$ \\
\hline Immediate Memory Task (IMT), Discriminability $\left(d^{\prime}\right)$ & $1.00(0.50)$ & $1.14(0.48)$ \\
\hline Immediate Memory Task (IMT), Response bias $(\beta)$ & $0.74(0.23)$ & $0.85(0.29)$ \\
\hline Go/Stop Task (STOP), 150 msec inhibition & $64.00(18.86)$ & $68.67(18.84)$ \\
\hline Go/No-Go Task (GNG), Commission errors & $17.37(9.70)$ & $15.76(8.12)$ \\
\hline \multicolumn{3}{|l|}{ Externalizing Traits/Disorders, mean (SD) } \\
\hline Barratt Impulsiveness Scale-11 (BIS-11) & $67.20(10.79)$ & $59.90(11.04)$ \\
\hline Sensation Seeking Scale V (SSS-V) & $23.70(5.99)$ & $17.23(6.89)$ \\
\hline Buss Warren Aggression Questionnaire (BUSS) & $45.50(13.40)$ & $37.57(10.37)$ \\
\hline Wender Utah Rating Scale for ADHD (WURS) & $37.93(14.12)$ & $22.83(14.17)$ \\
\hline Antisocial Personality Disorder (ASPD), \# of symptoms & $2.73(1.66)$ & $0.67(1.09)$ \\
\hline Psychopathy Checklist (PCL:SV) & $10.87(5.08)$ & $3.10(3.46)$ \\
\hline \multicolumn{3}{|l|}{ Internalizing Traits/Disorders, mean (SD) } \\
\hline Beck Depression Inventory II (BDI-II), & $7.17(3.92)$ & $6.53(5.99)$ \\
\hline Hopelessness, Substance Use Risk Profile (SURPS) & $11.43(2.83)$ & $11.60(3.08)$ \\
\hline Anxiety Sensitivity Index (ANXSI) & $21.30(0.44)$ & $17.00(9.60)$ \\
\hline State Anxiety (STAI) & $32.40(5.37)$ & $31.83(7.92)$ \\
\hline Toronto Alexithymia Scale (TAS) & $46.24(8.93)$ & $42.60(10.28)$ \\
\hline
\end{tabular}


pioRxiv preprint doi: https://doi.org/10.1101/480970; this version posted November 29 2018. The copyright holder for this preprint (which was

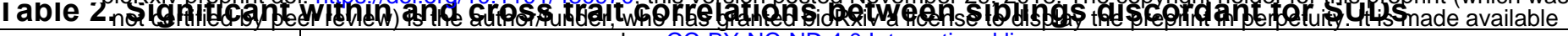

\begin{tabular}{|c|c|c|}
\hline \multirow[t]{2}{*}{$\log (x)$} & \multicolumn{2}{|c|}{ 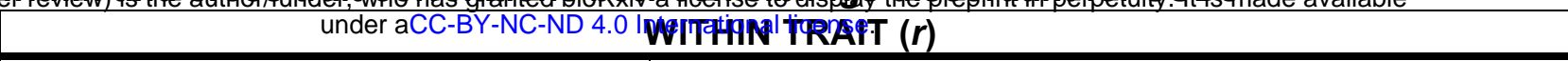 } \\
\hline & Discordant Heroin Pairs & Discordant Amphetamine Pairs \\
\hline \multirow{3}{*}{$\begin{array}{l}\text { Neurocognitive } \\
\text { Measures }\end{array}$} & \multirow{3}{*}{$\begin{array}{l}\text { CGT Delay Aversion (0.383) } \\
\text { BART Pumps Adj. Avg. (0.359) }\end{array}$} & CGT Quality of Decision Making (0.389) \\
\hline & & IMT Discriminability $(0.373)$ \\
\hline & & GNG Commission Errors (0.368) \\
\hline \multirow{2}{*}{$\begin{array}{l}\text { Externalizing } \\
\text { Traits/Disorders }\end{array}$} & \multirow{2}{*}{ SSS-V (0.398) } & BIS-11 (0.412) \\
\hline & & WURS (0.367) \\
\hline \multirow[t]{3}{*}{$\begin{array}{c}\text { Internalizing } \\
\text { Traits/Disorders } \\
\end{array}$} & SURPS-H (0.509) & ANXSI (0.562) \\
\hline & \multicolumn{2}{|r|}{ CROSS TRAIT $(r)$} \\
\hline & Discordant Heroin Pairs & Discordant Amphetamine Pairs \\
\hline $\begin{array}{l}\text { Neurocognitive } \\
\text { Measures }\end{array}$ & $\begin{array}{l}\text { MCQ Inc \& MCQ k (-0.365) } \\
\text { IMT Discriminability \& STOP }(0.335) \\
\text { IMT Response Bias \& STOP }(0.521) \\
\text { GNG Commission Errors \& IMT } \\
\text { Discriminability }(-0.337)\end{array}$ & $\begin{array}{l}\text { IGT Total \& CGT Quality of Decision Making (-0.396) } \\
\text { CGT Delay Aversion \& STOP (0.387) } \\
\text { MCQ Inc \& MCQ k (0.481) } \\
\text { BART Pumps Adj. Avg. \& IGT Total (-0.425) } \\
\text { IMT Discriminability \& IMT Response Bias (-0.455) } \\
\text { IMT Response Bias \& CGT Delay Aversion (0.447) } \\
\text { STOP \& IMT Discriminability (-0.372) } \\
\text { STOP \& GNG Commission Errors }(0.409) \\
\text { GNG Commission Errors \& IMT Discriminability }(-0.458) \\
\text { GNG Commission Errors \& IMT Response Bias }(0.503)\end{array}$ \\
\hline \multirow{6}{*}{$\begin{array}{l}\text { Externalizing } \\
\text { Traits/Disorders }\end{array}$} & & BIS-11 \& WURS (0.415) \\
\hline & BIS-11 \& PCL:SV (-0.422) & SSS-V \& BIS-11 (0.420) \\
\hline & WURS \& BIS-11 (-0.382) & WURS \& BIS-11 (0.384) \\
\hline & WURS \& PCL:SV (-0.375) & WURS \& BUSS (0.462) \\
\hline & ASPD \& BIS-11 (-0.403) & PCL:SV \& BUSS (0.489) \\
\hline & & PCL:SV \& WURS (0.357) \\
\hline $\begin{array}{l}\text { Internalizing } \\
\text { Traits/Disorders }\end{array}$ & $\begin{array}{l}\text { BDI-II \& SURPS-H }(0.533) \\
\text { BDI-II \& TAS }(0.485) \\
\text { SURPS-H \& TAS }(0.662) \\
\text { STAI-S \& SURPS-H }(0.472) \\
\text { STAI-S \& TAS }(0.459)\end{array}$ & BDI-II \& ANXSI (0.361) \\
\hline
\end{tabular}

Note. The full correlation matrices for neurocognitive measures, externalizing traits/disorders, and internalizing traits/disorders are shown in Supplemental Tables 1, 2, and 3, respectively. Directionality of the IGT and STOP tasks were reversed so that higher scores indicate higher impulsivity. 
bioRxiv preprint doi: https://doi.org/10.1101/480970; this version posted November 29, 2018. The copyright holder for this preprint (which was

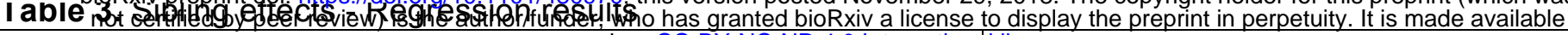
under aCC-BY-NC-ND 4.0 Internationdl licensibling Pairs Discordant for Heroin

Dependence, $N=37$

\section{Neurocognitive Measures}

lowa Gambling Task (IGT), Net Score*

Beta (SE)

$-0.147(0.219)$

$0.436(0.219)$

$0.061(0.117)$

$-0.029(0.197)$

$-0.145(0.540)$

$0.431(0.201)$

$0.181(0.144)$

$-0.086(0.197)$

$0.013(0.214)$

Go/Stop Task (STOP), 150 msec inhibition

Go/No-Go Task (GNG), Commission errors

\section{Externalizing Traits/Disorders}

Barratt Impulsiveness Scale-11 (BIS-11)

Sensation Seeking Scale (SSS-V)

Buss Warren Aggression Questionnaire (BUSS)

Wender Utah Rating Scale for ADHD (WURS)

Antisocial Personality Disorder (ASPD), \# of symptoms ${ }^{* *}$

Psychopathy Checklist (PCL:SV) ${ }^{\star *}$

\section{Internalizing Traits/Disorders}

Beck Depression Inventory II (BDI-II) ${ }^{* *}$

Substance Use Risk Profile (SURPS), Hopelessness subscale

Anxiety Sensitivity Index (ANXSI)

State-Trait Anxiety Inventory (STAI), State Anxiety subscale

Toronto Alexithymia Scale (TAS)

$0.089(0.129)$

$0.397(0.165)$

$0.019(0.179)$

$-0.050(0.107)$

$-0.401(0.288)$

$0.001(0.038)$

$0.031(0.037)$

$0.448(0.188)$

$0.008(0.152)$

$0.000(0.283)$

$0.332(0.165)$
Neurocognitive Measures

lowa Gambling Task (IGT), Total*

Cambridge Gabling Task (CGT), Delay aversion

Cambridge Gabling Task (CGT), Quality of decision making

Monetary Choice Questionnaire (MCQ), Log overall $k$

Monetary Choice Questionnaire (MCQ), \# of inconsistencies

Balloon Analogue Risk Task (BART), Pumps adjusted average

Immediate Memory Task (IMT), Discriminability $\left(d^{\prime}\right)$

Immediate Memory Task (IMT), Response bias $(\beta)$

Go/Stop Task (STOP), 150 msec inhibition*

Go/No-Go Task (GNG), Commission errors

\section{Externalizing Traits/Disorders}

Barratt Impulsiveness Scale 11 (BIS)

Sensation Seeking Scale V (SSS)

Buss Warren Aggression Questionnaire (BUSS)

Wender Utah Rating Scale for ADHD (WURS)

Antisocial Personality Disorder (ASPD), \# of symptoms **

Psychopathy Checklist (PCL:SV) ${ }^{\star *}$

\section{Internalizing Traits/Disorders}

Beck Depression Inventory II (BDI-II) ${ }^{* *}$

Substance Use Risk Profile (SURPS), Hopelessness subscale

Anxiety Sensitivity Index (ANXSI)

State-Trait Anxiety Inventory (STAI), State Anxiety subscale

Toronto Alexithymia Scale (TAS)

$\mathbf{0 . 4 6 9}(\mathbf{0 . 1 3 6 )}$
$0.003(0.241)$

Sibling Pairs Discordant for

Amphetamine Dependence, $\mathbf{N}=\mathbf{3 0}$

\begin{tabular}{|c|c|}
\hline $\boldsymbol{p}$-value \\
0.509 \\
0.059 \\
0.608 \\
\hline 0.883 \\
0.790 \\
\hline $\mathbf{0 . 0 4 0}$ \\
0.217 \\
\hline 0.664 \\
\hline 0.952 \\
\hline 0.990 \\
\hline \\
\hline 0.498 \\
\hline $\mathbf{0 . 0 2 2}$ \\
0.916 \\
\hline 0.641 \\
\hline 0.164 \\
\hline 0.971 \\
\hline 0.400 \\
\hline $\mathbf{0 . 0 2 8}$ \\
0.956 \\
\hline 1.000 \\
\hline 0.056 \\
\hline
\end{tabular}

Beta

$-0.016(0.207)$

$-0.196(0.220)$

$0.838(0.446)$

$-0.036(0.233)$

$0.169(0.389)$

$0.266(0.187)$

$0.327(0.175)$

$0.115(0.243)$

$0.131(0.199)$

$0.314(0.158)$

$p$-value

$0.448(0.191)$

$-0.129(0.209)$

$0.220(0.146)$

$0.393(0.183)$

$-0.010(0.217)$

$0.058(0.052)$

$0.036(0.050)$

$-0.124(0.254)$

$-0.434(0.299)$

$-0.198(0.226)$
0.938

0.383

0.074

0.879

0.669

0.168

0.073

0.639

0.514

0.059

0.027

0.541

0.143

0.041

0.963

0.263

0.468

0.632

$\mathbf{0 . 0 0 2}$

0.159

0.388

Note. *The direction of effect was reversed for the IGT and STOP variables so that higher scores reflect higher impulsivity, to be consistent with all other measures. ${ }^{* *}$ Negative binomial regressions were run for ASPD,

$\mathrm{PCL}: S V$, and BDI due to zero-inflation. All models included age and sex as covariates. 